\title{
PENTINGNYA STOCK OPNAME KOLEKSI PERPUSTAKAAN IPDN KAMPUS JAKARTA
}

\author{
BOGA PRATALA \\ Pustakawan Muda IPDN Kampus Jakarta \\ Email: bpratala@yahoo.com
}

\begin{abstract}
ABSTRAK
Penelitian ini membahas tentang stock opname di Kampus IPDN Jakarta. Tujuan dari penelitian ini adalah untuk mengetahui kelebihan dan kekurangan dari koleksi stock opname. Kegiatan ini menggunakan metode kualitatif berupa studi kasus. Pengumpulan data dilakukan dengan observasi, wawancara, dokumentasi. Ada tiga informan dalam penelitian ini, yaitu kepala sekolah, guru, dan staf perpustakaan. Hasil penelitian ini menunjukkan bahwa perpustakaan Kampus IPDN Jakarta melakukan stock opname dengan metode daftar/registrasi berisi nomor induk. Manfaat dari penelitian ini adalah mengetahui kondisi bahan pustaka agar dapat dilakukan tindakan pemberantasan terhadap koleksi yang tidak layak, sehingga dapat dilakukan pengembangan koleksi, sehingga memudahkan dalam mencari bahan pustaka. Di sisi lain, membutuhkan waktu pengumpulan data yang singkat, orang tidak dapat meminjam koleksi selama kegiatan. Dapat disimpulkan bahwa stock opname koleksi perpustakaan Kampus IPDN Jakarta hanya menggunakan metode register/registrasi yang memuat nomor induk. Dengan melakukan stock opname Kampus IPDN Jakarta ini, dapat diketahui koleksi perpustakaan yang sebenarnya.
\end{abstract}

Kata kunci: Koleksi Buku, Perpustakaan Universitas, Stock Opname, Kampus IPDN Jakarta

\begin{abstract}
This research discusses about stock opname collection at IPDN Kampus Jakarta. The purpose of this study was determining the advantages and disadvantages of stock opname collections. This activity uses a qualitative method in the form of case study. Data collection was conducted by the observation, interview, documentation. There were three informants in this study, namely the principal, teacher, and library staff. The results of this study indicate that the librarian of IPDN Kampus Jakarta did stock opname with the method of list / registration containing the parent number. The advantage of this research is knowing the condition of library materials in order to take eradication measures for collections that are not feasible, so that the development of collections can be done, making it easier to find library materials. On the other hand, it requires a short amount of data collection time, people cannot borrow collections during the activity. It can be concluded that stock opname library collection of IPDN Kampus Jakarta just use the register/ registration method containing the parent number. By doing this stock opname of IPDN Kampus Jakarta, the real collection of library could be found out.
\end{abstract}

Keywords: Book Collections, University Library, Stock Opname, IPDN Kampus Jakarta

\section{PENDAHULUAN}

Sebagaimana diamanatkan Undang-Undang Nomor 43 Tahun 2007 tentang perpustakaan dijelaskan bahwa perpustakaan adalah institusi pengelola koleksi karya tulis, karya cetak, dan karya rekam secara professional dengan sistem yang baku guna memenuhi kebutuhan pendidikan, penelitian, pelestarian, informasi, dan rekreasi para pemustaka. Perpustakaan sebagai sarana penyedia informasi yang keberadaanya selalu dinanti oleh pemustaka, khususnya bagi pemustaka yang sedang menempuh jenjang pendidikan. Oleh karena itu, perpustakaan berperan penting dalam mencerdaskan anak bangsa.

Perpustakaan perguruan tinggi adalah perpustakaan yang berada pada lingkungan perguruan tinggi, perguruan tinggi tinggi, akademi atau perguruan tinggi tinggi lainnya yang pada hakikatnya merupakan bagian integral dari suatu perguruan tinggi. Perpustakaan perguruan tinggi memilih, mengolah, mengoleksi, merawat, dan melayankan koleksi yang 
dimilikinya kepada para warga lembaga induknya pada khususnya dan masyarakat akademis pada umumnya.

Proses pendidikan diperguruan tinggi tidak terlepas dari kegiatan penelitian dan pengembangan, inovasi, serta rekayasa ilmu pengetahuan. Sehingga perpustakaan perguruan tinggi sering dikatakan "jantungnya" Universitas. Khusus perpustakaan perguruan tinggi ini berkembang istilah lain yaitu, college library, kurang lebih disertakan dengan perpustakaan akademi.

Sebagai bagian dari institusi perguruan tinggi, perpustakaan diselenggarakan dengan tujuan untuk menunjang pelaksanaan program perguruan tinggi sesuai dengan Tri Dharma Perguruan Tinggi, yaitu pendidikan dan pengajaran, penelitian serta pengabdian kepada masyarakat. Untuk menunjang pendidikan dan pengajaran, perpustakaan di lingkungan perguruan tinggi mengumpulkan, mengolah, menyimpan, menyajikan dan menyebarluaskan informasi untuk mahasiswa dan dosen sesuai dengan kurikulum yang berlaku. Untuk menunjang penelitian, perpustakaan perguruan tinggi mengumpulkan, mengolah, menyimpan, menyajikan dan menyebarluaskan informasi bagi peneliti baik intern institusi atau ekstern di luar institusi. Untuk menunjang pengabdian kepada masyarakat, perpustakaan perguruan tinggi melakukan kegiatan dengan mengumpulkan, mengolah, menyimpan, menyajikan dan menyebarluaskan informasi bagi masyarakat.

Pada dasarnya tugas perpustakaan perguruan tinggi secara umum adalah menyusun kebijakan dan melakukan tugas rutin untuk mengadakan, mengolah dan merawat bahan pustaka serta mendayagunakan untuk kepentingan civitas akademika pada khususnya dan masyarakat pada umumnya. Untuk mengetahui aset yang dimiliki oleh perpustakaan perguruan tinggi, stock opname memegang peranan yang sangat penting sebagai pertimbangan dalam pengembangan koleksi perpustakaan perguruan tinggi. Menurut Wince (2017), perpustakaan perguruan tinggi perlu melaksanakan stock opname pada waktu tertentu sehingga tercapailah tujuan pengembangan koleksi yang sesuai dengan kebijakan instansi dan kebutuhan pemustaka.

Perpustakaan IPDN Kampus Jakarta berusaha untuk memenuhi kebutuhan yang dibutuhkan oleh pemustaka dengan memberikan pelayanan yang baik. Perpustakaan juga merupakan sistem informasi yang berfungsi untuk menyediakan dan menyampaikan informasi yang berfungsi untuk menyediakan dan menyampaikan informasi yang terdapat dalam koleksinya. Karena itu, koleksi perpustakaan harus diolah, diatur sedemikian rupa sehingga informasi yang terdapat dalam koleksinya dapat disimpan dan ditemukan kembali secara cepat dan tepat.

Perpustakaan yang baik harus bisa mengadakan koleksi sesuai kebutuhan pengguna, mengolah informasi atau koleksi, menyediakan informasi, dan memberikan informasi yang sesuai kepada pengguna. Oleh karena itu kegiatan stock opname perpustakaan juga merupakan kegiatan yang penting bagi perpustakaan.

Stock Opname merupakan kegiatan menghitung ulang kembali koleksi yang ada di perpustakaan. Pentingnya stock opname untuk diterapkan pada Perpustakaan IPDN Kampus Jakarta dikarnakan petugas dapat mengetahui yang mana koleksi yang rusak dan yang mana koleksi yang masih kokoh, dengan stock opname petugas atau pustakawan bisa mengetahui apa saja koleksi yang ada di perpustakaan, jumlah koleksi begitu juga nomor klasifikasinya. Kemudian dengan adanya kegiatan ini petugas mendapat hasil akhir dari kegiatan stock opname koleksi adalah laporan riil koleksi pada perpustakaan.

Pada stock opname koleksi perpustakaan IPDN Kampus Jakarta ini melakukan dengan cara manual ini memerlukan waktu yang sangat lama karena memiliki koleksi yang banyak dan petugas tidak boleh keliru dalam menjalani tugasnya, terlaksananya stock opname akan menimbulkan ketidaknyamanan terhadap pemustaka karena pada kegiatan ini tidak boleh ada pemustaka yang meminjam buku dan bagi pemustaka yang telah meminjam buku sebelum kegiatan ini dimulai maka pemustaka harus segera mengembalikan buku yang telah dipinjam. Pada kegiatan ini dimulai petugas langsung menjalani tugasnya dengan mengeluarkan seluruh buku yang ada di rak kemudian memisahkan buku dengan sesuai nomor klasifikasinya, 
memisahkan yang mana buku rusak, dan buku yang tidak ada nomor klasifikasinya, kemudian disusun kembali ke rak sesuai dengan nomor klasifikasinya karena agar mudah untuk menemukan informasi yang dibutuhkan oleh pemustaka dan memberikan kemudahan pustakawan dalam membantu pemustaka untuk mencari informasi.

Kegiatan stock opname pada Perpustakaan harusnya menjadi kegiatan yang harus dilakukan setiap periode untuk mengetahui dengan tepat berapa jumlah keseluruhan koleksi perpustakaan, jumlah koleksi yang hilang, koleksi yang rusak, dan memerlukan beberapa perbaikan, serta mengetahui dengan tepat koleksi yang sudah tidak layak lagi untuk disediakan di jajaran koleksi perpustakaan (Panggabean: 2017).

Proses stock opname yang masih terbilang cukup lambat, karena prosesnya dilakukan dengan cara mengetikkan satu persatu kode buku ke dalam sistem. Salah satu solusi untuk mengatasi permasalahan tersebut adalah dengan membuat aplikasi barcode scanner pada mobile device berbasis sistem operasi Android (Sastrawangsa, et.al: 2020).

Penggunaan aplikasi dalam Stock Opname terkadang masih menemui beberapa kendala. Namun kendala tersebut diharapkan dapat diperbaiki pada saat Stock Opname berlangsung oleh IT Development yang turut membantu (Budirahman: 2018).

Pada penelitian ini akan dilakukan pembuatan aplikasi barcode scanner android dan siitegrasikan dengan SLiMS. Dengan digunakannya aplikasi ini, proses stock opname dapat dilakukan dengan mudah dan cepat, serta perpustakaan tidak perlu lagi mengeluarkan biaya untuk membeli barcode scanner.

Belakangan ini pemustaka mendefinisikan perpustakaan hanyalah ruang atau gedung yang didalamnya terdapat buku, majalah,surat kabar untuk dipinjamkan definisi inilah yang membuat pandangan pustakawan hanyalah sebagai penjaga buku, jika diperhatikan dengan teliti, gedung, ruangan, ini tempat menyimpan informasi. Informasi merupakan data yang diolah yang berguna untuk penggunanya, tempat penyimpanan informasinya berbagai bentuk yaitu tertulis, terekam, tercetak seperti CD, flash disk, peta, buku, majalah, lembaran dan sebagainya demikian itu perpustakaan bukan hanya sekedar menyimpan buku, majalah, surat kabar dan sebgainya, akan tetapi perpustakaan juga menyimpan informasi demikian sebaliknya. Pustakawan sebagai pekerja informasi yang bertugas mengelola isi perpustakaan dan sebagai layanan informasi dikarenakan adanya perkembangan maka informasi juga semakin lama semakin berkembang sesuai dengan perkembangan ilmu pengetahuan.

Berdasarkan latar belakang diatas penulis, mempertimbangkan pentingnya kegitan stock opname koleksi di perpustakaan agar mempermudah pekerjaan pustakawan sehingga pemustaka bisa menemukan informasi yang di inginkannya, maka penulis bermaksud untuk menggali informasi lebih dalam mengenai "Pentingnya Stock Opname Koleksi di Perpustakaan IPDN Kampus Jakarta" dengan metode studi kasus yang menguji Stock Opname Koleksi di Perpustakaan IPDN Kampus Jakarta.

\section{METODE PENELITIAN}

Penelitian ini menggunakan metode studi kasus yang menguji secara rinci suatu tempat, orang, subjek, tempat penyimpanan dokumen, atau peristiwa tertentu dalam penulis mengenai stock opname koleksi di perpustakaan IPDN Kampus Jakarta. Penulis mengambil lokasi penelitian di perpustakaan IPDN Kampus Jakarta yang berada di Jl. Ampera Raya, kota Jakarta Selatan.

Data dan sumber data, data primer dalam penulisan ini diperoleh dari petugas perpustakaan, jumlah informan dalam penelitian ini sebanyak tiga orang terdiri atas kepala perguruan tinggi, petugas perpustakaan,dan guru. Data sekunder merupakan sumber data yang didapat dari hasil observasi, wawancara, dan dokumentasi. Observasi (penulis melakukan pengamatan di lapangan khususnya di perpustakaan IPDN Kampus Jakarta), wawancara (merupakan percakapan yang dilakukan oleh penulis kepada narasumber untuk mendapatkan informasi Stock opname koleksi Perpustakaan IPDN Kampus Jakarta), dokumentasi (penulis melakukan dokumentasi untuk mengumpulkan informasi yang berkaitan dengan stock opname 
koleksi di perpustakaan IPDN Kampus Jakarta). Kegiatan ini dilakukan dengan menggunakan kamera. Sumber data dalam penelitian ini diperoleh dan didapat dari informan terdiri atas kepala perguruan tinggi, guru, dan petugas perpustakaan.

Dokumentasi dilakukan untuk memperoleh informasi tentang stock opname perpustakaan IPDN Kampus Jakarta. Adapun alat-alat pengumpulan data yang digunakan dalam penulis ini sebagai berikut, Pedoman Observasi, alat yang digunakan untuk membantu penulis dalam melakukan observasi berupa pedoman observasi/pengamatan. Dalam melakukan observasi penulis melihat langsung kejadian di lapangan agar dapat lebih mudah melihat apa yang sudah terjadi di Perpustakaan IPDN Kampus Jakarta. Pedoman Wawancara, Pada pedoman ini berupa pertanyaan yang disusun secara sistematis yang ditanyakan langsung dengan lisan kepada Kepala perguruan tinggi, Petugas perpustakaan, dan guru di Perpustakaan IPDN Kampus Jakarta. Dokumentasi, alat yang digunakan untuk membantu dalam penelitian perpustakaan adalah Kamera yang digunakan untuk mengambil gambar, dan video, untuk memperoleh data dokumentasi di Perpustakaan IPDN Kampus Jakarta.

Tahap selanjutnya adalah menganalisis data. Analisis data merupakan proses mengorganisasikan, mengurutkan data kedalam pola,kategori, dan mengatur sehingga dirumuskan simpulan. Maka dalam penelitian ini menggunakan model analisis data Miles dan Huberman (1984: 63) dalam analisis data memiliki tiga proses yaitu "data reduction, data display, dan data drawing/verification.

\section{HASIL DAN PEMBAHASAN}

\section{Hasil Observasi/Pengamatan di lapangan}

Kegiatan stock opname di lingkungan perpustakaan Kampus IPDN Jakarta dilakukan pada tanggal 1 Agustus 2021 sampai dengan 31 Agustus 2021 dengan pembagian tugas sebagai berikut:

Tabel 1. Pembagian Tugas Stock Opname

\begin{tabular}{|c|l|l|}
\hline No & \multicolumn{1}{|c|}{ Nama } & \multicolumn{1}{|c|}{ Tugas } \\
\hline 1 & Okti Hendaryanti, S.Pd & Penanggung Jawab \\
\hline 2 & Boga Pratala, S.sos & $\begin{array}{l}\text { Koordinator Pelaksana } \\
\text { Perancang kerja dan sistem } \\
\text { Operator verifikasi data }\end{array}$ \\
\hline 3 & Nina Anggraini, S.IP, MPA & $\begin{array}{l}\text { Perancang kerja dan sistem } \\
\text { Operator verifikasi data }\end{array}$ \\
\hline 4 & Meylinda Fitria C & Operator dan Verifikasi Data \\
\hline 5 & Sri Ariningsih & Operator dan Verifikasi Data \\
\hline 6 & Abdul Muis & Operator dan Verifikasi Data \\
\hline 7 & Memen & Operator dan Verifikasi Data \\
\hline 8 & T. Aris & Operator dan Verifikasi Data \\
\hline 9 & Ramli & Operator dan Verifikasi Data \\
\hline 10 & Enda & Operator dan Verifikasi Data \\
\hline 11 & Jena & Reshelving dan Logistik \\
\hline 12 & Kompres & Reentri data dan Barcoding \\
\hline 13 & Supri & Reentri data dan Barcoding \\
\hline 14 & Andri & Reentri data dan Barcoding \\
\hline
\end{tabular}


Secara garis besar proses stock opname di lingkungan Perpustakaan Kampus IPDN Jakarta melalui software SLIMS (Senayan Library Information Management System) adalah sebagai berikut:

1. Buka SLIMS (Senayan Library Information Management System)

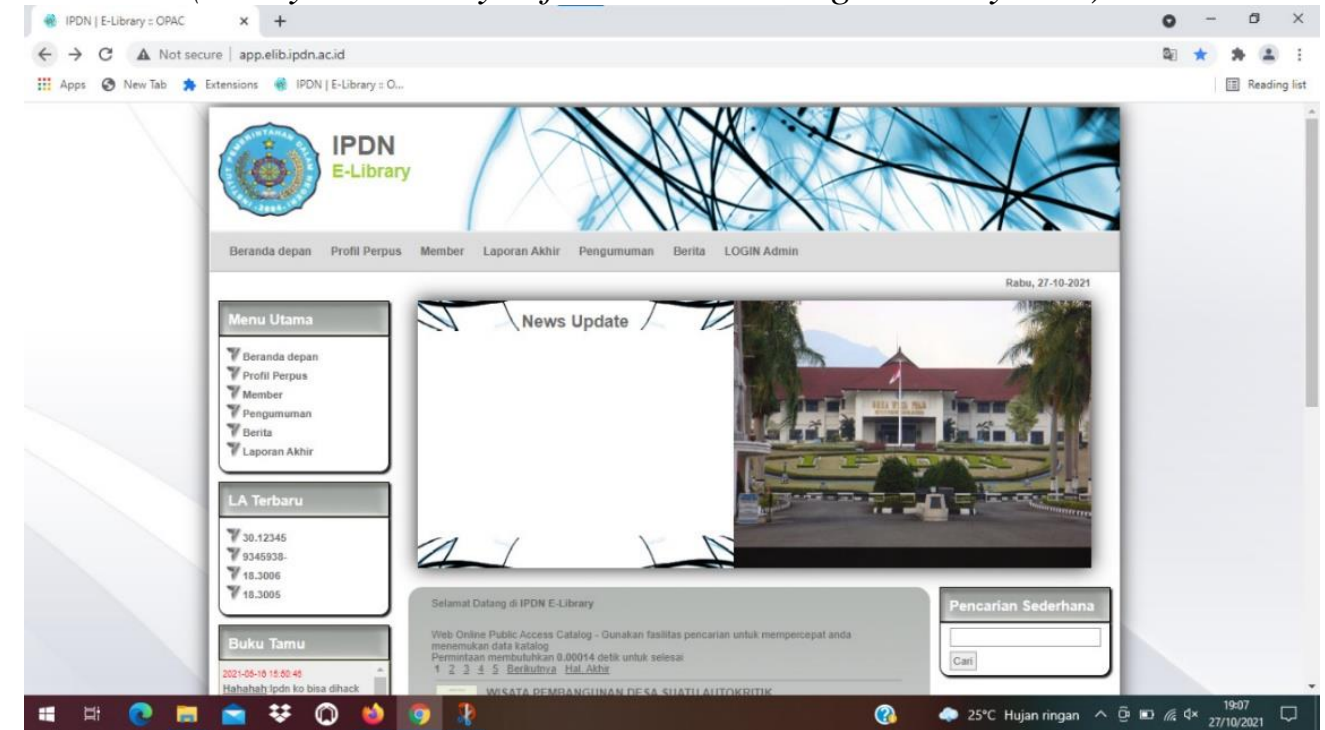

\section{Gambar 1. Tampilan Awal SLIMS (Senayan Library Information Management System)}

2. Sebelum memulai stock opname dengan software SLIMS (Senayan Library Information Management System), kita harus melakukan login terlebih dahulu, yaitu dengan mengisi user name dan password kemudian klik login.

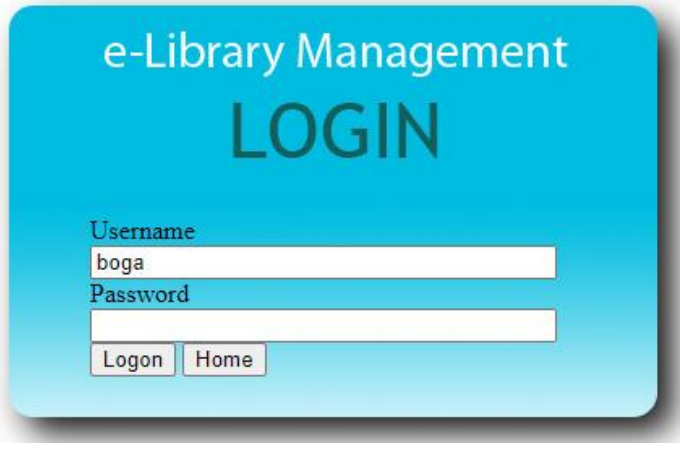

\section{Gambar 2. Tampilan Login Admin}

3. Setelah login selesai, kemudian kita memilih salah satu menu dari beberapa menu yang ada. Untuk melakukan stock opname kita memilih menu Inventarisasi.

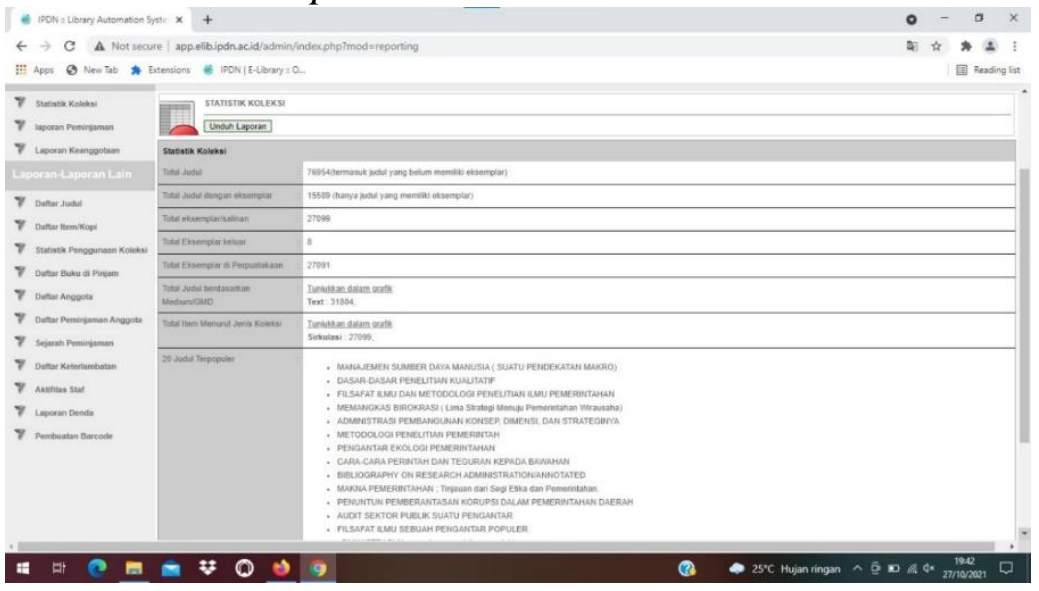

Gambar 3. Tampilan Inventarisasi 
4. Masukkan Nomor induk buku ke dalam kode eksemplar untuk mengetahui keberadaan koleksi tersebut di dalam database.

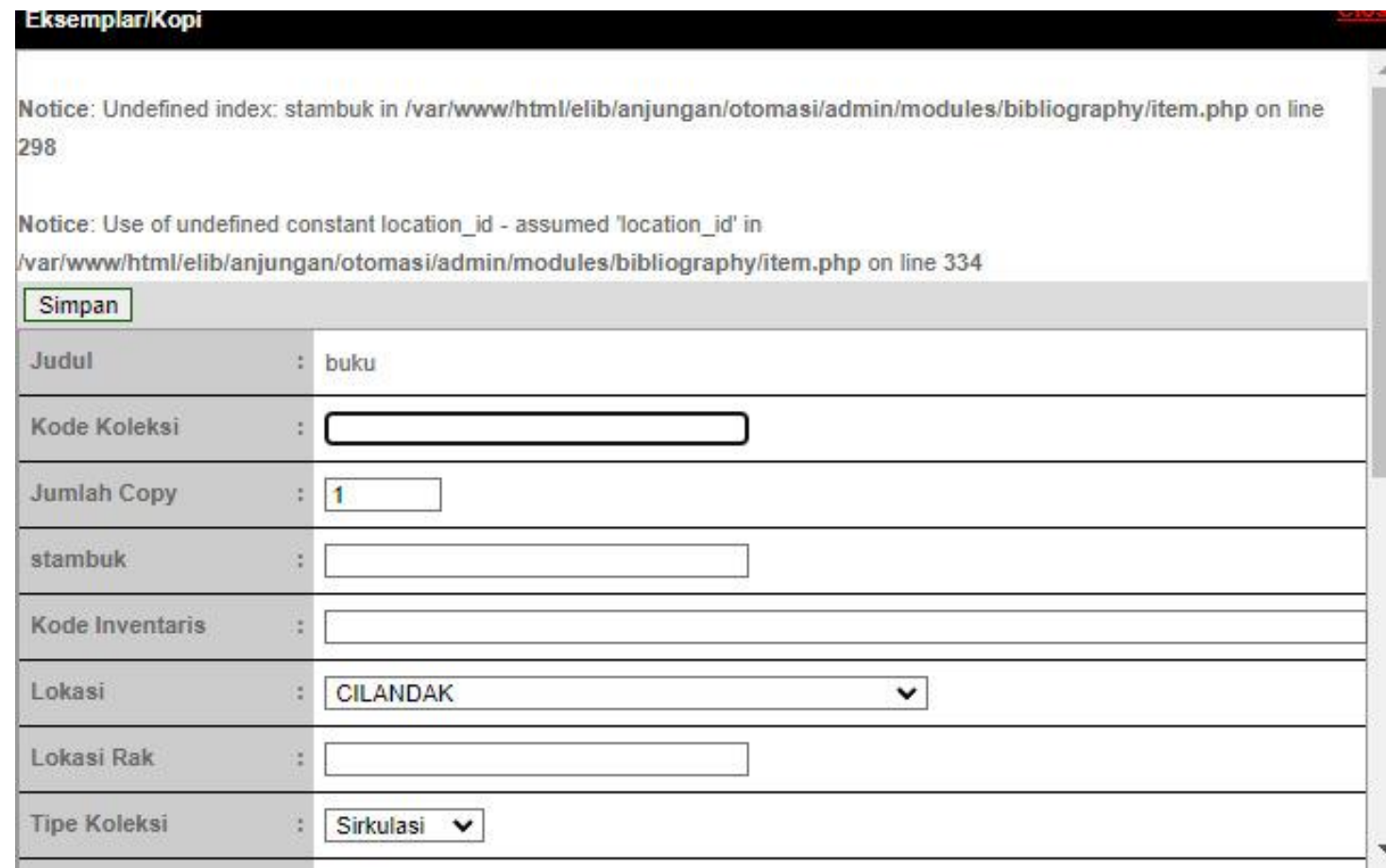

Gambar 4. Tampilan Nomor Induk Buku

5. Jika koleksi buku tersebut ada dalam database, maka kode eksemplar dan judul buku statusnya ada. Tampilannya sebagai berikut :

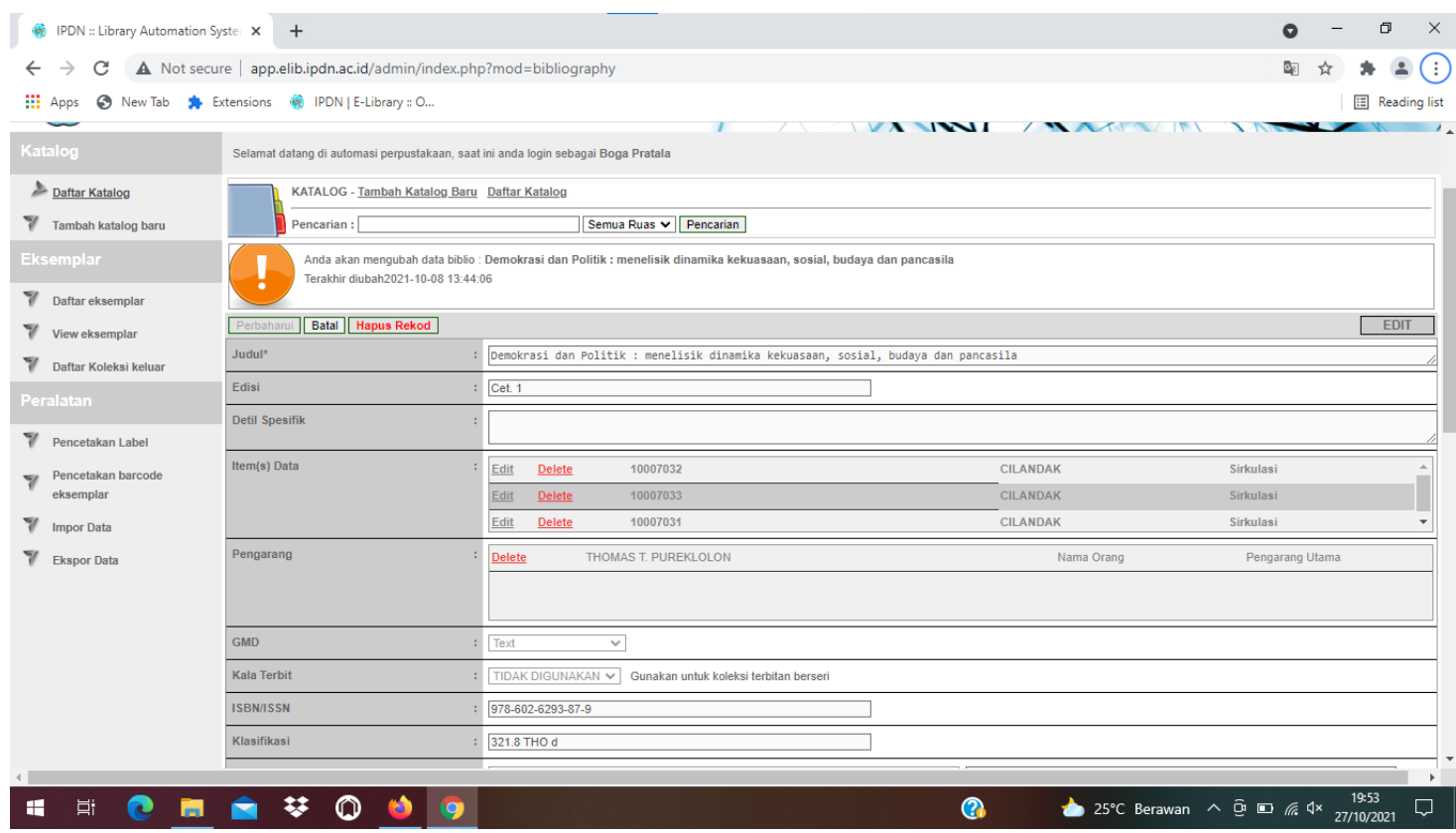

Gambar 5. Tampilan Koleksi ada didalam Database 
6. Jika koleksi buku tersebut tidak ada, maka kode eksemplar dan judul buku tidak muncul dan ada keterangan di dalam kolom warna merah. Tampilannya sebagai berikut :

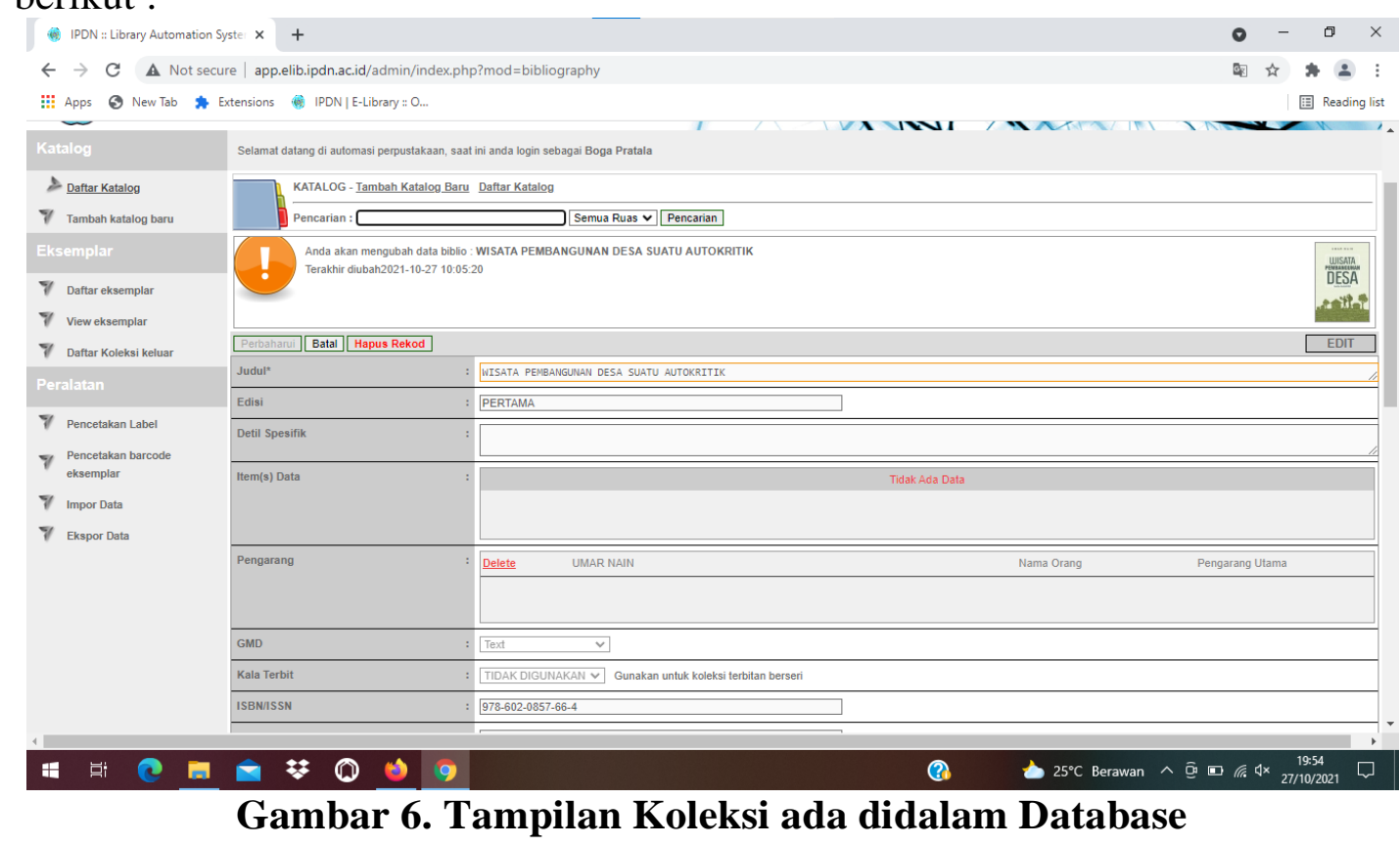

Selain itu, pustakawan saat memeriksa buku satu persatu di rak khususnya terkait keterangan apakah buku tersebut dalam keadaaan baik atau rusak sebagaimana tertera dalam tabel 2 dibawah ini.

Tabel 2. Data Buku Rusak di lingkungan Kampus IPDN Jakarta

\begin{tabular}{|c|c|c|c|c|c|c|c|c|c|}
\hline No & JULULBUKU & PENGaRRANG & PENERBIT & KLARFFIKASS| & BARCODE & dMML- & \multicolumn{2}{|c|}{ BAHASA } & THN \\
\hline & Practical Methods Of Increassing Productivity Manufacturing Industries & & Geneveva & $658.5 \mathrm{lnt}$ & 11116696 & 6] & $\sqrt{7}$ & & 1953 \\
\hline & L'Adaptation De La Machine a'L'Homme & A.Chapanish & With English Translation & $658.56 \mathrm{Cha}$ & 11118739 & 9 & $\bar{T}$ & & \\
\hline & Perbandingan Hak Milik Alas Tanah Dan RechtV Van Eigendomm & A. TelukiSH & PT. Eresco D.J.L.Géusanulun 1 & & & 1 & & 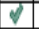 & 1966 \\
\hline & Laporan Akkhir Study Kasus Penentuan Jabatan Wakil Dan Pembantu Gubenur Kepala Daer ah & \multicolumn{2}{|c|}{ Pusat Peneltitian Dan Pembangunan Pemerinthan Daer ah } & 3520.0598 Dep & & 1 & & $\overline{7}$ & 1980 \\
\hline & Beberapa Aspek Fembangunan DiK Kabupaten Daerah Tingkat2 2 Sukabuumi & Departemen Penerangan Fi & & & & 2 & & $\nabla$ & 1979 \\
\hline & Fidato Fresiden Pada Pembuka Kan Kongres Kehutanan Sedunia Ke 8 Pada Tangal 16 Okt 1978 Di Jakarta & & & & & 2 & & $\sqrt{2}$ & \\
\hline & Pandai Berenang & & Diembatan & 797.2Dja & 1119067 & 7 & & $\sqrt{2}$ & \\
\hline & Buku Panduan Aku Cinta Rumath Susun & & & 648 Dae & & 3 & & 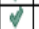 & \\
\hline & Segi-SegiPerusahàan Dari Padda Pers & dale b. stafford & Jajassan lembaga pers dan pendapat umum & $070.3 \mathrm{StaS}$ & 1100450 & (1) & & 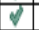 & 1957 \\
\hline & Grote Ondernemingen En Hun Leiders & eernest dale & makkaboeken & & & 1 & 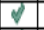 & & 1965 \\
\hline & Australia ln Facts And Figures & & & 919.4 A Us & 11119605 & 51 & 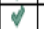 & & 1969 \\
\hline & Pidato Pressiden Soekarnoe Pada Pertemuan Dengan Para Peserta Sajembara Proyek Tugu Nasional Li Listana Negara Dijakarta & Departemen Penerangan $\mathrm{Fi}$ & & 736.5500 & 1119037 & 1 & & $\nabla$ & 1960 \\
\hline 14 & 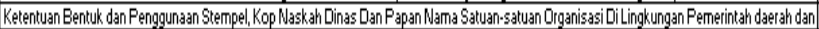 & ni departemen dalam negeril & & \multicolumn{2}{|l|}{352.0598 Dep K } & 3 & & $\sqrt{2}$ & 1983 \\
\hline 15 & Rdministrtative science quatrefly & robert vpreshtus ed & & $350.5 \mathrm{Adm}$ & & 1 & 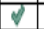 & & 1961 \\
\hline 16 & Laporan penelitian Kapasitas managaemen pembangunan di tingkat kecamatan & nusa konsullant PT & & 350.1Nus 1 & & 1 & & $\nabla$ & 1988 \\
\hline & Laporan akhir KKN institute ilmu pemerintahan departemen dalam negeri bekeriassama dengan pemerintah dki jakatta & departemen dalam negeri & & 371.2Dep 1 & & 1 & & 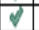 & 1985 \\
\hline 18 & Peranan pendidikan dan lathan dalam pembinàn mental pegawai & dt. soeroso sm. Hk. & yayazann Karya darma & 350.15 Soep & & 2 & & $\sqrt{7}$ & 1986 \\
\hline 19 & siklus angagaran negara republik indoinesia & harlyono sumosudirio sh & yayasan karya darma & $336.91 \mathrm{Sum} \mathrm{S}$ & & 4 & & $\nabla$ & 1978 \\
\hline 22 & 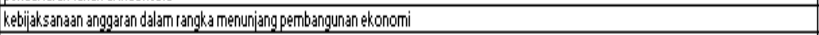 & arimultyse & & $336.598 \mathrm{ArnK}$ & & 1 & & $\sqrt{4}$ & 1985 \\
\hline $23 \mid$ & facts about the united states & united states internation service & & 919.73 Uni & 11196657 & 1 & $\bar{N}$ & & 1951 \\
\hline & 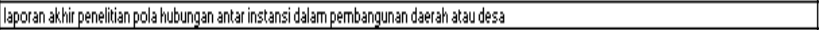 & lembaga administrasinegarda & & \multicolumn{2}{|l|}{352.0598 Lem L } & 1 & & $\nabla$ & 1978 \\
\hline 25 & population dynamics ethics and policy & margatertmead & american association for the advencement of scier & 301.3ReiF & 1103134 & 1 & $\nabla$ & & 1975 \\
\hline 26 & factor ecologis suatu tinjayan & roessdibiono & Panitia wisuda ke VIIIII jakarta & 301.3Roe $\mathrm{F}$ & 1033136 & 1 & $\sqrt{2}$ & & 1978 \\
\hline 27 & 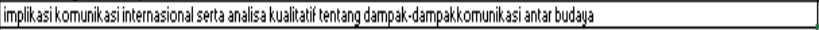 & & Lembaga aresearch kebudaydyan nassional lipi & 301.2lemi & & 1 & & 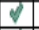 & 1987 \\
\hline $28 \mathrm{~L}$ & laporan prakkekek kerijalapangan ikarya bhakki praja & mahasiswa aip (thun 199111992 & ipdnijkartta & 371.2 & & 1 & & 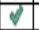 & 1991 \\
\hline & personnel psychology & & ajounal of applied research & $658.305 \mathrm{Per}$ & 11118180 & 1 & $\bar{a}$ & & 1960 \\
\hline & 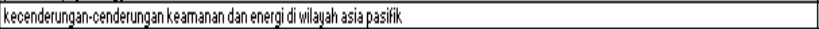 & & lembaga research kebudayaan nasional lipi & 301.2LemI & 1102693.98 & 2 & & $\nabla$ & 1982 \\
\hline & doktrin hank amnas dan doktrin periuangan abri ekka karma & & pb pepabri & & & 1 & & $\sqrt{2}$ & \\
\hline & menuju pembangunan terpaduyang berswadaya & ib.w kuiten brower & lembaga studio pembangunan & 335.5 kuicl & & 1 & & 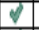 & \\
\hline 33 & administrtasi pemerintahan perancis & dr. Sarwoto & & 5444 & & 1 & & 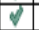 & \\
\hline & nak administrtasi pemerintath daer ah propinsi sulawesi tengath tahun 1974 & & & $352091 \mathrm{pem}$ & & 1 & & 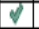 & 1974 \\
\hline 35 & Letrs policy & drs. Sudijiono mbs & & $650 \mathrm{bam}$ & & 2 & & $\sqrt{2}$ & 1969 \\
\hline
\end{tabular}

\section{Hasil wawancara}

Kegiatan stock opname di lingkungan perpustakaan Kampus IPDN Jakarta menggunakan metode daftar/registrasi yang berisi nomor induk. Berdasarkan informan, Ibu Okti Hendaryanti (12 Agustus 2021) menyampaikan bahwa,"pada kegiatan ini petugas menggunakan 
daftar/registrasi yang berisi nomor induk karena dalam kegiatan ini dikerjakan dengan manual petugas meminta bantuan kepada bagian Menza namun metode ini yang digunakan dikarenakan menurut petugas metode ini yang paling mudah dikerjakan, petugas menyebutkan nomor induk yang ada di bahan pustaka sedangkan petugas yang lain membantu mememberi tanda pada nomor induk dan memeriksa di dalam daftar".

Pada kegiatan stock opname koleksi di perpustakaan IPDN Kampus Jakarta memiliki beberapa keuntungan berdasarkan informan ibu Okti Hendaryanti (12 Agustus 2021) mengatakan keuntungan yaitu : 1.agar bisa mengetahui kondisi bahan pustaka(petugas langsung mendatangi ke rak buku dan melihat langsung kondisi bahan pustaka dalam kondisi rusak dan tidaknya pada bahan pustaka). 2.agar dapat mengambil tindakan penghapusan bagi koleksi yang tidak layak,( maksudnya petugas telah melakukan pengecekan terhadap bahan pustaka kemudian menemukan bahan pustaka yang rusak parah atau yang tidak bisa di perbaiki lagi dan menemukan koleksi yang tahunya sudah kadaluarsa, maka dari itu petugas langsung mengambil tindakan penghapusan bahan pustaka). 3.agar bisa dilakukan pengembangan koleksi perpustakaan IPDN Kampus Jakarta, (Maksudnya kegiatan stock opname koleksi juga dapat membantu untuk pengembangan koleksi dikarenakan kegiatan ini petugas dapat mengetahui jumlah kolesi baik koleksi yang hilang, rusak, dan koleksi yang tidak layak dipakai oleh karena itu petugas mengambil tindakan untuk mengadakan pengembangan koleksi dan mempertimbangkan koleksi apa saja yang dibutuhkan oleh pengguna/pemustaka).

Berdasarkan informan bapak Muiz dan ibu Sri Ariningsih (12 Agustus 2021) mengatakan keuntungan "Mempermudah dalam menemukan bahan pustaka" Maksudnya pada stock opname koleksi petugas telah mengetahui letak bahan pustaka dikarenakan pada kegiatan ini petugas sudah melakukan pengecekan koleksi dan mengklasifikasikan koleksi maka apabila pemustaka ingin mencari koleksi yang di inginkan akan di temukan dengan mudah.

Pada kegiatan stock opname koleksi di perpustakaan IPDN Kampus Jakarta juga memiliki kerugian, berdasarkan informan Ibu Okti Hendaryanti (12 agustus 2019). 1.memberi rasa ketidaknyamanan bagi pengunjung. Maksudnya pada kegiatan Stock opname koleksi pemustaka/pengunjung tidak diperbolehkan masuk dan meminjam bahan pustaka karena agar tidak menggangu petugas dalam melakukan kegiatan ini) 2.memerlukan waktu pendataan yang tidak sebentar (maksudnya dikarenakan pada kegiatan stock opname koleksi ini tidak memerlukan waktu yang sebentar) berdasarkan informan bapak Muiz dan ibu Sri Ariningsih (12 Agustus 2021) mengatakan kerugiannya yaitu."tidak dapat meminjam koleksi selama kegiatan berlangsung".

\section{Pembahasan}

Berdasarkan pernyataan petugas perpustakaan IPDN Kampus Jakarta menggunakan dengan metode daftar/registrasi, namun sedangkan menurut Sulisttyo-Basuki (dalam Yulia dan Janti) ada beberapa metode yang dilakukan pada stock opname koleksi yaitu menggunakan daftar pengadaan, menggunakan daftar/registrasi yang berisi nomor induk, lembar lepas berisi nomor induk, kartu uji, menghitung dokumen/koleksi, dengan bantuan komputer. Pada kegiatan stock opname koleksi di perpustakaan IPDN Kampus Jakarta hanya menggunakan metode daftar/registrasi, namun dengan menggunakan satu metode ini sudah bisa melakukan kegiatan stock opname koleksi di perpustakaan IPDN Kampus Jakarta.

Sedangkan menurut yulia dan janti (2011: 8.26-8.27) adapun beberapa keuntungan yang didapat pada kegiatan stock opname koleksi yaitu: 1.Dapat disusun daftar dokumen yang perlu disiangi sudah tidak sesuai lagi baik dari segi subjek, tahun, dan kondisi dokumen, 2. Dengan diketahuinya dokumen yang hilang, menunjukan dokumen tersebut diminati pengguna, Hal ini sebagai bahan pertimbangan dalam pengadaan dokumen, 3.Dapat diketahui laju kehilangan dokumen di suatu perpustakaan, 4.Dapat diperoleh susunan dokumen yang rapi dan sesuai dengan urutan di rak. 5.Dapat dilakukan pembersihan dokumen dari debu dan kotoran lainya.

Berdasarkan pernyataan diatas bahwa keuntungan stock opname koleksi itu untuk mempermudah penyusunan daftar dokumen yang perlu disiangi dan sudah tidak sesuai lagi, 
untuk mempermudah dalam mengetahui dokumen yang hilang serta dapat mengetahui lajunya kehilangan dokumen di perpustakaan, memepermudah susunan dokumen yang rapi sesuai urutan di rak, dan dapat dilakukan pembersihan dokumen dari kotoran.

Sedangkan menurut yulia dan janti (2011: 8.26-8.27) adapun beberapa kerugian yaitu; 1. Mengurangi kenyamanan bagi pengguna karena selama kegiatan semua dokumen yang sedang dipinjam ditagih untuk untuk dikembalikan, 2. Selama kegiatan stock opname, banyak perpustakaan tidak memberikan pelayanannya kepada pengguna. Hal ini kurang diinginkan pengguna, 3. Memerlukan biaya relatif mahal.

Berdasarkan pernyataan diatas kerugian stock opname koleksi maksudnya ialah perpustakaan tidak berjalan dengan optimal karena kurangnya kenyamanan bagi pengguna dan perpustakaan tidak memberikan pelayanan dengan optimal terhadap pemustaka serta biaya yang relatif mahal. Agar kegiatan stock opname dapat berjalan dengan lancar dan cepat, sebaiknya perpustakaan tidak melakukan pelayanan selama kegiatan berlangsung (Subagio: 2019).

Perpustakaan Perguruan Tinggi merupakan salah satu jenis perpustakaan yang diselenggarakan di lingkungan perguruan tinggi. sama halnya dengan jenis perpustakaan perguruan tinggi yang lainnya, perpustakaan perguruan tinggidapat diartikan sebagai tempat terhimpunnya berbagai bahan pustaka, baik cetak maupun noncetak seperti, buku, majalah, surat kabar, film, video, dan CD guna menunjang kegiatan pembelajaran di perguruan tinggi yang bersangkutan. Semua bahan pustaka yang tersedia di perpustakaan perguruan tinggi disusun, di tata, dan dikelola berdasarkan sistem tertentu yang disesuaikan dengan tuntutan dan kebutuhan para penggunanya yaitu para mahasiswa perguruan tinggi. Penyusunan, penataan,dan pengelolaan, bahan pustaka yang dimaksudkan untuk memberikan kemudahan kepada para pengguna perpustakaan di dalam mencari, menemukan dan memanfaatkan bahan pustaka tersebut. Adapun sistem yang digunakan untuk menyusun, menata, dan mengelola perpustakaan perguruan tinggi bisa secara sederhana (manual) maupun secara elektronik menggunakan komputer sebagai saranannya .

koleksi adalah bahan perpustakaan yang merupakan terjemahan dari library materials istilah lain bahan tersebut dikenal dengan istilah dokumen terjemah dari document. Istilah yang digunakan untuk bahan perpustakaan ataupun dokumen adalah bahan pustaka. Sedangkan kumpulan bahan pustaka yang terdapat di perpustakaan dikenal dengan istilah koleksi perpustakaan. Semua istilah tersebut pada intinya adalah ditujukan untuk sebuah karya hasil pemikiran manusia yang di tuangkan berbagai bentuk media. (Yulia dan janti, 2011:1.19)

Salah satu komponen perpustakan yaitu koleksi. Tanpa adanya koleksi yang baik dan memadai maka perpustakaan tidak akan memberikan layanan yang baik kepada masyarakat pemakainya. Dalam hal ini, yang dimaksud dengan koleksi perpustakaan adalah semua bahan pustaka yang dikumpulkan, diolah dan disimpan untuk di sebarluaskan kepada masyarakat guna memenuhi kebutuhan informasi mereka.

Menurut Yulia dan Janti (2011: 8.26-8.27) Kegiatan ini biasa disebut dengan stock opname yang merupakan suatu kegiatan penghitung kembali koleksi dokumen yang dimiliki perpustakaan. Kegiatan ini diharapkan dapat memenuhi kebutuhan akan diperolehnya profil koleksi, jajaran katalog yang tersusun rapi serta dapat mencerminkan keadaan koleksi suatu perpustakaan karena hal ini dapat meningkatkan pelayanan kepada pengguna. Kegiatan ini sering ditambakan dengan kegiatan penyiangan koleksi yaitu untuk mencari dokumen yang tidak berguna lagi misalnya subjek dan tahun terbitan yang sudah tidak sesuai lagi. Stock opname biasanya memerlukan waktu yang cukup lama. Untuk itu, bagi perpustakaan kecil bisa dilakukan setahun sekali dan untuk perpustakaan perpustakaan besar paling sedikit 2-3 tahun sekali.

\section{KESIMPULAN}

Berdasarkan hasil penelitian dan pembahasan hasil maka di peroleh kesimpulan sebagai berikut: (1)Dapat disimpulkan bahwa kegiatan stock opname koleksi memiliki beberapa 
metode yaitu menggunakan daftar pengadaan, menggunakan daftar/registrasi yang berisi nomor induk, lembar lepas berisi nomor induk, kartu uji, menghitung dokumen/koleksi, dengan bantuan komputer, Sedangkan kegiatan stock opname koleksi di perpustakaan IPDN Kampus Jakarta hanya menggunakan metode daftar/registrasi namun dengan menggunakan satu metode ini sudah bisa melakukan kegiatan stock opname koleksi di perpustakaan IPDN Kampus Jakarta.(2)Selanjutnya kegiatan stock opname koleksi ini memiliki keuntungan untuk mempermudah penyusunan daftar dokumen yang perlu disiangi dan sudah tidak sesuai lagi, untuk mempermudah dalam mengetahui dokumen yang hilang serta dapat mengetahui lajunya kehilangan dokumen di perpustakaan, memepermudah susunan dokumen yang rapi sesuai urutan di rak, dan dapat dilakukan pembersihan dokumen dari kotoran. Sedangkan kerugiannya perpustakaan tidak berjalan dengan optimal karena kurangnya kenyamanan bagi pengguna dan (3) perpustakaan tidak memberikan pelayanan dengan optimal terhadap pemustaka serta biaya yang relatif mahal.

\section{DAFTAR PUSTAKA}

Budirahman, Subagja dan Erika. (2018).Penggunaan Near Field Communication dalam Kegiatan Stock Opname di Library \& Knowledge Center Binus International University. Visi Pustaka, Vol. 20 Nomor 2

Panggabean, Siti Khodizzah. (2017). Evaluasi Stock Opname Pada Dinas Perpustakaan Dan Kearsipan Pemerintahan Kota Medan. Medan: Universitas Sumatera Utara.

Sastrawangsa, Gde dkk. (2020). Otomatisasi Stock Opname Pada Senayan Library Management System. CSRID Journal, Vol. 12 No. 1.

Subagio, Ilham dan Antonius Totok Priyadi. Stock Opname Koleksi Perpustakaan Sekolah Dasar Negeri 34 Pontianak Kota. Pontianak: Perpustakaan FKIP Untan Pontianak.

Sulistyo-Basuki. (1991). Pengantar Ilmu Perpustakaan . Jakarta: Gramedia Pustaka Utama. Undang-undang Nomor 43 Tahun 2007 Tentang Perpustakaan.

Wince, Eka. (2017). Kajian Pentingnya Stock Opname Dalam Pengembangan Koleksi Perpustakaan. Sekolah Tinggi Agama Islam Negeri (STAIN) Curup: Jurnal Ilmu Perpustakaan dan Informasi.

Yulia, yuyu. (1993). Pengadaan Bahan Pustaka. Jakarta: Universitas Terbuka 